


\section{Organisation and delivery of home mechanical ventilation}

\section{Educational aims}

I To analyse home mechanical ventilation (HMV) from a community perspective.

1 To analyse healthcare delivery alternatives.

I To consider different sources of variability in clinical practice.

I To emphasise the role of patients in the decision-making process.

\section{Summary}

The number of patients using HMV is increasing in all Western countries. There has been a significant increase in the number of obese patients and - despite the restrictive recommendations of the guidelines - of patients with chronic obstructive pulmonary disease (COPD). In most countries, there are no systematic registers of patients, outcomes are not followed regularly and support at home is very variable.

It is very important to think about how to organise the care of patients on HMV: it must seek a balance between the role of reference centres and accesibility to local hospitals. Networking should be a reasonable alternative.

\footnotetext{
The European study on HMV (the Eurovent survey) is a point of reference for analysing the patterns of use of this therapy [1]. The study had some methodological limitations, particularly related to the identification of centres and the accuracy of the estimated prevalence.

However, the large number of patients (more than 23,000 patients studied) and the detailed analysis of each country of the European Union (as it stood in 2002) allowed the identification of some factors that should be considered when analysing HMV: patterns of care for patients requiring HMV were highly variable; current registers of patients exist only in Sweden and Denmark; and the indication criteria were highly variable (the proportion of patients with COPD differs greatly between countries) and offered little data concerning the results of HMV (survival, hospitalisation, etc.). Aside from the differences between countries, differences within each individual country were also observed [2].
}

Comparative studies on HMV are difficult to assess in view of differences between the health systems of each country, problems in the registration of cases, and variability in experience in this type of treatment: there are countries that have treated patients at home for more than 40 years (and they are equipped with a well-organised and mature system of expertassisted support), while other countries have only started with this treatment in the past 5-10 years. Above all, the sharing of information is an opportunity to improve this form of treatment.

In the JIVD meeting (International Conference on Home Mechanical Ventilation) held in Barcelona in March 2009, a "round table" discussion took place concerning HMV in Europe and America, with the participation of B. Fauroux (Paris, France), N.S. Hill (Boston, MA, USA), M.J. Kampelmacher (Utrecht, the Netherlands), B. Midgren (Lund, Sweden), J.F. Muir (Rouen, France), B. Schönhofer (Hanover, Germany), A.K. Simonds (London, UK), Z. Szkulmowski (Bydgoszcz, Poland) and A.

\section{J. Escarrabill \\ Master Plan for Respiratory \\ Diseases (PDMAR) \\ Institutd'Estudis de la Salut \\ C/ Roc Boronat \\ 81-951stfloor \\ 08005 Barcelona \\ Spain \\ jescarrabill@gencat.cat}

\section{Provenance}

Reportfrom JIVD meeting (International Conference on Home Mechanical Ventilation, held in Barcelona in March 2009), peer reviewed

Competing interests None declared 
Vianello (Padua, Italy). In the present article, we identify various points which describe in detail the problems related to HMV, via a survey of the members of the round table prior to the meeting, the opinions of experts and comments from participants in the debate.

Table 1 is a summary of the elements that enable the description of HMV. Comparison between countries is very challenging in view of the heterogeneity in the nature of health services and the levels of HMV development. However, the analysis of the elements that define HMV could suggest possible changes in both the delivery of services and their quality.

\section{Prevalence}

The estimated prevalence of HMV in the areas studied is twice the average prevalence identified in the Eurovent survey. There is a wide variation between countries and the appropriate prevalence is difficult to identify. Sweden, with its very

\section{Table 1 Elements that enable the description of home mechanical ventilation}

\begin{tabular}{|c|c|}
\hline Number of cases & $\begin{array}{l}\text { Number of patients per 100,000 inhabitants (cross section) } \\
\text { Number of new cases per 100,000 inhabitants per year }\end{array}$ \\
\hline Prescription & $\begin{array}{l}\text { Referral centre versus community hospitals } \\
\text { Prescription restricted to certain specialists versus access to } \\
\text { prescription to any doctor } \\
\text { Financing }\end{array}$ \\
\hline Register of cases & $\begin{array}{l}\text { Official global registration } \\
\text { Registration in each centre } \\
\text { Publication of data }\end{array}$ \\
\hline Follow-up of patients & $\begin{array}{l}\text { Systematic organisation of clinical follow-up of patients } \\
\text { Centres that initiate ventilation without follow-up } \\
\text { Risk management }\end{array}$ \\
\hline Home care & $\begin{array}{l}\text { Directly through the prescribing centre } \\
\text { Role of private suppliers } \\
\text { Coordination with community resources } \\
\text { Telemedicine and/or telemonitoring }\end{array}$ \\
\hline Equipment & $\begin{array}{l}\text { Access to a diverse range of equipment } \\
\text { Importance of support to perform activities of daily living }\end{array}$ \\
\hline Outcomes & $\begin{array}{l}\text { Measurement of results: } \\
\text { Survival } \\
\text { Admissions } \\
\text { Health professionals' visits (outpatient clinics and emergency } \\
\text { departments) } \\
\text { Quality of life }\end{array}$ \\
\hline Organisation & $\begin{array}{l}\text { Centralisation } \\
\text { Networks }\end{array}$ \\
\hline
\end{tabular}

precise register, has a rate of cases double that of the Netherlands, which also has a strict system of control. The elevated number of cases in France does not necessarily indicate an ideal point. It is difficult to explain the differences in the prevalence when considering only the absolute figures. Differences in prevalence of neuromuscular diseases or COPD are not so wide as to justify significant differences in the case rate. To explain this variability, different elements must be considered: experience in ventilation (years of use of the technique in a country), the healthcare system (accessibility to specialists, community resources and hospital documentation) and the beliefs/ confidence of the professionals in the efficacy of the treatment, among others.

HMV has risen in all countries studied, independent of the initial prevalence (figure 1).

\section{Prescription}

In most countries, prescription is done in a referral centre or in a general hospital, but in $25 \%$ of cases the location where the prescription occurs is heterogeneous and, in practice, any doctor can do it (particularly in France and the USA).

The prescription of HMV presents a dilemma concerning the convenience of identifying specific referral centres (with the experience to care for a large number of patients) or accepting prescription in hospitals closest to the patient (increasing accessibility, but also increasing the risk of not having a critical mass of patients sufficient to maintain the clinical skills necessary to correctly perform the procedure and respond to incidents). Therefore, the dilemma is of expertise versus accessibility; however, it is in fact a false dilemma. From the perspective of patient the choice between expert centres and nearby hospitals is clear: both options are ideal. Therefore, from the perspective of the patient both the technical competence of the focal point and the accessibility are important issues.

The diffusion of technology raises the issue of the impact of a learning curve in centres $[3,4]$. This learning curve can be minimised by means of formal training courses, supervised practice or direct support from experts in the first stages of learning. Simulation could play an important role in minimising the learning curve. As with all technology that is applied to a growing number of patients, it is improbable that a treatment procedure can maintain itself exclusively in "referral centres". The growing number of patients, espe- 
centres". The growing number of patients, especially those who suffer from obesity, will make HMV unsustainable in referral centres alone. The solution is to create networks. Centres can be connected in non-hierarchical networks, within which are designed care plans for patients.

The prescription of noninvasive ventilation does not necessarily require hospital admission $[5,6]$. However, if patients are clearly not in a stable situation or live far from the hospital, an admission of 4-5 days can be more useful than starting the ventilation in an outpatient clinic; without this there could be a significant impact on hospital resources.

The most frequently used form of airway access is through noninvasive interface, mainly via nasal ventilation. Access through a tracheostomy is seen in a minority of cases in most countries (probably less than $5 \%$ of cases). However, in northern Italy, 40\% of neuromuscular patients were ventilated via tracheostomy (which represents $30 \%$ of all ventilated patients).

\section{Register of cases}

The registration of cases has been in place in Sweden since 1996, through the Swedish Society of Chest Medicine and the health authorities [7]. Thus, the Swedish register can monitor HMV: from an initial prevalence of 6.2 patients per 100,000 inhabitants, there was a prevalence 10.5 per 100,000 in 2002, and more than 21 patients per 100,000 inhabitants in 2008.

This increase of patients (tripling in case numbers in only 8 years) is mainly due to the increase in patients who suffer from obesity-hypoventilation syndrome. Other interesting data from the register is the identification of the number of new cases per year. Based on the Swedish register, there is an estimated 3-4 new cases annually per 100,000 inhabitants. Catalonia also produces 4-5 new indications of HMV per year per 100,000 inhabitants. This number is an approximation that must be related to the more mature prescription system. When the number of prescriptions increases, so does the number of indicated cases.

A register is a good tool to aid knowledge of the situation concerning HMV and the results obtained [8], but it requires time and resources. The absence of a register of patients does not imply that HMV is out of control. However, prescribers should have data on the type of patients on HMV and the outcomes; their own data and comparisons are good regulatory mechanisms.

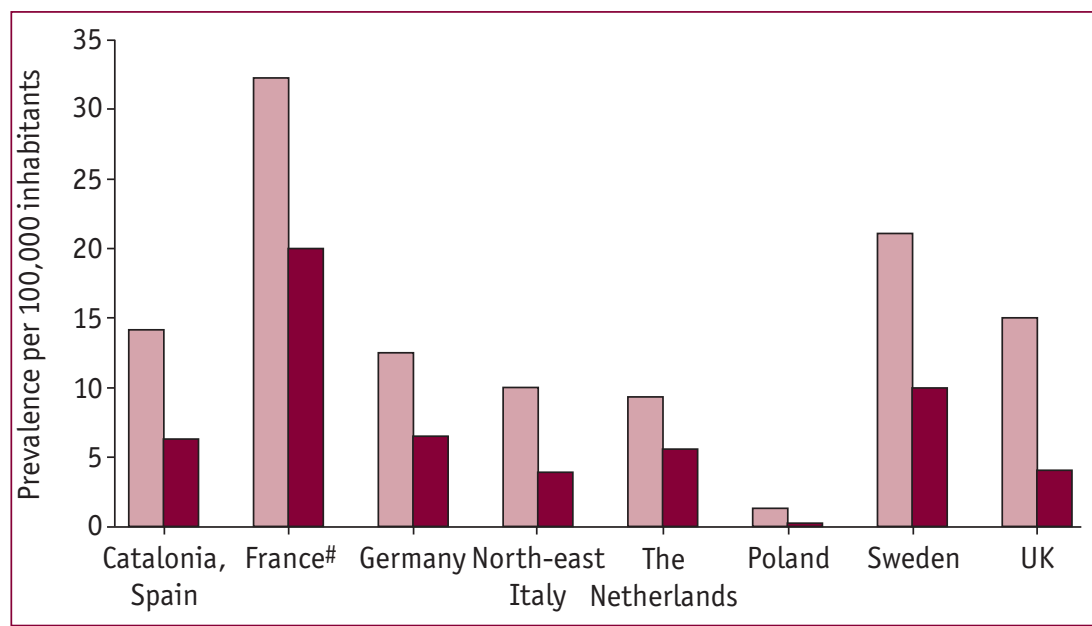

Some non-profit organisations, such as ANTADIR (Association Nationale pour les Traitements à Domicile, les Innovations et la Recherche [National Association for Home Treatments, Innovation and Research]), have had a register in place for many years, but the ANTADIR register does not include the private sector.

\section{Follow-up}

According to the JIVD round table members, long-term follow-up is mainly carried out by the prescribing centre. However, in $27 \%$ of cases this following up is variable. Only in $30 \%$ of cases is the connection between the prescribing centre and community resources systematic and wellorganised (figure 2).

Organised and systematic monitoring of patients with HMV is essential. The indication of HMV without an explicit plan for follow-up is not good practice. Monitoring can be done through the centre itself or through other healthcare resources. Monitoring is essential because of the severity of the respiratory failure itself. But, besides this, it can highlight problems with home delivery, if there is no immediate improvement.

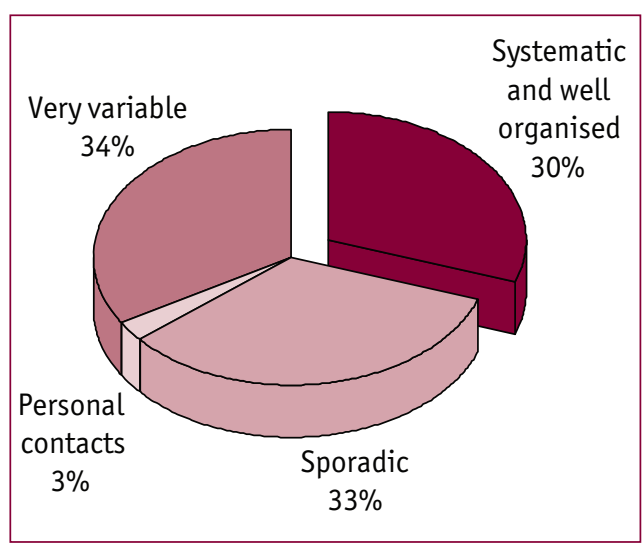

Figure 1

The prevalence of HMV is increasing in all countries, according to data from the Eurovent survey. $\square$ : JIVD 2009; 口: Eurovent 2002. \#: not including paediatric patients.

\section{Figure 2}

The relationship of the prescribing centres with resources in the community is not always smooth and systematic. Population: 291,500,000. 
For example, it may be necessary to adjust the ventilator settings. Moreover, HMV does not guarantee the stability of the disease causing respiratory failure. Thus, weight changes or changes in neuromuscular disease may require changes in ventilator parameters, increasing the duration of ventilation, complementary techniques, such as mouth ventilation [9], or making decisions concerning the switch to invasive ventilation through tracheostomy [10].

The training of the team [11], well-designed discharge plans [12] and the education of the patient and the caregiver is crucial to minimising the risk [13]. Accessibility to the healthcare team, clinical data and the guarantee of technical support services at home are also essential from the point of view of risk management.

\section{Home care}

In $70 \%$ of cases, home care is implemented through a referral centre, but in nearly a quarter of cases, the responsibility is left with private providers. Home care is composed of two very different aspects: technical support (24 hours a day, 7 days a week, and 365 days a year) and clinical care. It is unlikely that a single healthcare organisation fulfils all the needs of patients. Care based on a prescriber centre ensures the skills and expertise, but at times may limit accessibility (especially with regard to distance). Cooperation between different healthcare services is not easy, but in many cases is the only way to respond to the needs of the patient.

Telemedicine or telemonitoring is a good tool in order to follow up patients with HMV [14]. It is important to have a clear objective in the use of communication technology: continued automation without an immediate solution is useless. However, these tools can be useful for assessing the patient over several days in order to identify slow and progressive worsening, to adjust the ventilation or to avoid unnecessary movements without any need of care.

With HMV, as with many chronic processes, the plan of care cannot be clearly defined without the active participation of the patient (and the carer) in their own treatment [15].

The round table participants stressed that whether the service is based on private insurance (USA) or on public health systems, in any case gives a total coverage of needs, so it is essential to involve the family. Ancillary care, such that given by a hospice, may be a great help, especially for the respite of the caregiver.
In the majority of countries home care is implemented by nurses; however, in some cases, for example in Poland, a doctor visits the patient's home once a week.

\section{Equipment and technical services}

There is now a wide variety of equipment and interfaces for performing HMV. Perhaps the only exception is the limited availability of a noninvasive interface for children (especially for very young children).

From a practical point of view, to provide HMV in adults it is not necessary to know all the equipment models available. In most cases, a range of four or five ventilators is sufficient to meet the needs of patients. It is very important to know the devices that are frequently used, in order to obtain maximum performance from them.

Sometimes, healthcare professionals discuss in depth the technical needs for improvement in HMV. In March 2008, the "Working for patients on home mechanical ventilation" workshop took place in Barcelona, organised by the Fundació Josep Laporte (Barcelona, Spain). The workshop highlighted the need for research on issues related to the organisation of care of patients with HMV rather than introducing new technologies. This hypothesis was summarised in an adaptation of the dissociation curve of haemoglobin.

Technical improvements are helpful but, in most countries, access to technology is already in the flat part of a sigmoid curve: investment in technology will produce little benefit (figure 3). In contrast, in most countries, small improvements in the organisation of care may have a major impact on patients. In the Barcelona workshop, attendees identified some of these improvements: information provision avoiding paternalism on the part of health professionals, promotion of self-care, more effective caregiver support (particularly through the promotion of social support networks) or removing architectural barriers and facilitating mobility of patients in suitable and adapted public transport.

In addition to the technical devices directly related to ventilation, the care needed by patients can be very complex. In northern Italy, the percentage of patients with amyotrophic lateral sclerosis ventilated via tracheostomy is very high. Burdens for families caring for these patients are very important, both in cost and time commitment. 


\section{Outcomes}

$45 \%$ of the participants in the JIVD round table did not perform regular monitoring of outcomes, and the other participants made casual analysis, but not in a systematic way. There is no gold standard for the comparison of the results of ventilation. Therefore, comparing the number of patients or types of diseases in which HMV is indicated gives partial information and is unhelpful. However, comparing the results obtained by different centres in one country (instead of just comparing diagnoses) may identify aspects of the treatment or the organisation of care that could be improved [16].

Besides survival, the number of admissions and length of stay, the number of visits or the quality of life of patients should also be known. In spite of everything, detailed comparisons on a regional level are more useful than caparisons between countries. In the Netherlands, prescribing centres meet once a year to exchange information about HMV. These exchanges of ideas and results should serve to identify priorities and opportunities for improvement.

\section{Organisation of care}

There is no single model of organisation of care that integrates long-term follow-up, home care, the role of private providers and support resources in the community. Very often the problems are more or less solved in metropolitan areas, where access to a referral centre is often easier, but dispersion increases the problems. As discussed in the section on prescription, the balance between referral centres and near-by hospitals is crucial.

In the UK the growth of networks has been noted. Networking is perhaps best the tool for the design of the plan of a patient's care and distribution of responsibilities among diverse health teams [17].

The organisation of care for patients with HMV is complex and, in some circumstances, there are not sufficient numbers of patients to warrant an organisation of its own. The integration of care of patients with non-specialists in HMV is sometimes inevitable and raises the problem of transmission of information and response to acute problems. As noted in the Netherlands, sometimes the team skilled in HMV is not primarily responsible for the care of patients.

In the organisation of care, it is very important to take into account the carer. The greatest

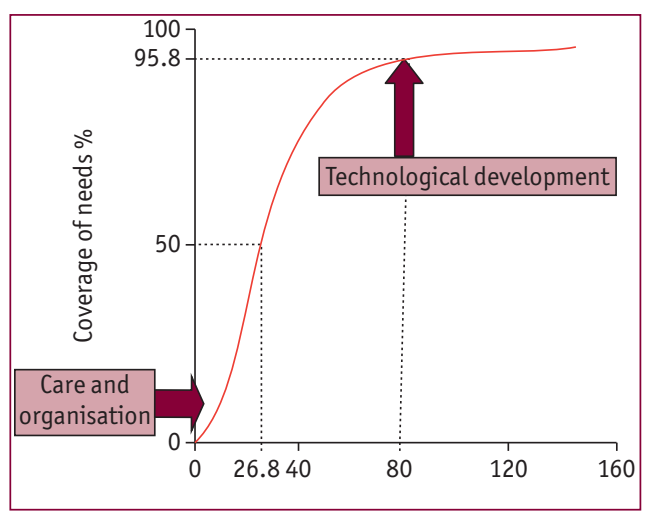

burden of care falls on the family. HMV is very difficult without this family support, and so is not easy in independently living patients. In the USA, "Carers for Independent Living" try to facilitate this independent living.

\section{Ventilation in children}

HMV was initiated in children during the polio epidemic and remained at highly specialised centres. In most countries the development of HMV in children is very recent [18]. HMV in children raises several problems. First, there is little material specifically tailored for children and often it is necessary to adapt equipment and materials designed for adults [19].

The role of the caregiver in HMV for children is even more important. Caregivers, although they have acquired many skills in the handling of the ventilator, have doubts and uncertainties, and they need support [20]. "Respite" programmes for the caregiver are important but, in general, the available resources are insufficient to meet needs. Conversely, the social impact of HMV in children is more important than in the case of adults. It is very important to do everything possible to facilitate the educational integration of children with HMV. In many cases, the presence in the classroom of a child with HMV requires a specific support for the teacher [21].

There is very little information about HMV in children. The French experience through the RespiRare $\subseteq$ project, created in 2007 in hospitals Armand Trousseau and Necker (Paris) and Centre Hospitalier Intercommunal (Créteil), is very interesting [22]. The RespiRare $\odot$ project attempts to meet the care needs of paediatric patients with rare diseases, grouped into four distinctive types: 1) pulmonary fibrosis and interstitial lung diseases, 2) ciliary dyskinesias, 3) chronic respiratory failure and 4) malformations of the respiratory system. The key tool of the project is the online
Figure 3

The impact of technology and care organisation. Sigmoid curve intended to graphically represent the hypothesis that to improve the organisation of care has more impact on the patient that the mere introduction of technical improvements. Technology needs are well covered (at the top of the sigmoid curve): increasing investment in technology will produce very little improvement in the coverage of needs. Care needs or the organisation of care in most countries is at the bottom of the sigmoid curve: small changes can achieve a great impact on the patient and their environment. 
registration of cases (allowing epidemiological studies) and an electronic medical record on the network that includes clinical, administrative and therapeutic information. This tool will also facilitate multicentre trials in order to improve research.

Finally, HMV is a treatment that will be used increasingly over the coming years, especially for treating patients with obesity-hypoventilation, and some patients with COPD. No single recipe for responding to the needs of these patients exists but, as suggested by experiences in Poland, work on a collaborative network can be imperative to sharing knowledge in this field and improving outcomes.

\section{References}

1. Lloyd-Owen SJ, Donaldson GC, Ambrosino N, et al. Patterns of home mechanical ventilation use in Europe: results from the Eurovent survey. Eur Respir J 2005; 25: 1025-1031.

2. Farre R, Lloyd-Owen SJ, Ambrosino N, et al. Quality control of equipment in home mechanical ventilation: a European survey. Eur Respir J 2005; 26: 86-94.

3. Hasan A, Pozzi M, Hamilton JR. New surgical procedures: can we minimise the learning curve? BMJ 2000; 320: 171-173.

4. Le Morvan P, Stock B. Medical learning curves and the Kantian ideal. J Med Ethics 2005; 31: 513-518.

5. Luján M, Moreno A, Veigas C, et al. Non-invasive home mechanical ventilation: effectiveness and efficiency of an outpatient initiation protocol compared with the standard in-hospital model. Respir Med 2007;101:1177-1182.

6. Chatwin M, Nickol AH, Morrell MJ, et al. Randomised trial of inpatient versus outpatient initiation of home mechanical ventilation in patients with nocturnal hypoventilation. Respir Med 2008; 102: 1528-1535.

7. Laub M, Berg S, Midgren B, et al. Home mechanical ventilation in Sweden - inequalities within a homogenous health care system. Respir Med 2004; 98: 38-42.

8. Laub M, Midgren B. Survival of patients on home mechanical ventilation: a nationwide prospective study. Respir Med 2007; 101: 1074-1078.

9. Toussaint M, Steens M, Wasteels G, et al. Diurnal ventilation via mouthpiece: survival in end-stage Duchenne patients. Eur Respir J 2006; 28: 549-555.

10. Marchese S, Lo Coco D, Lo Coco A. Outcome and attitudes toward home tracheostomy ventilation of consecutive patients: a 10-year experience. Respir Med 2008; 102: 430-436.

11. Escarrabill J, Goldberg A. Training the home health team. In: Ambrosino N, Goldstein R (eds). Ventilatory Support for Chronic Respiratory Failure. New York, Informa Health Care, 2007; pp. 000-000.

12. Pratt P, Escarrabill J. Discharge and follow-up. In: Ambrosino N, Goldstein R (eds). Ventilatory Support for Chronic Respiratory Failure. New York, Informa Health Care, 2007; pp. 000-000.

13. Simonds AK. Risk management of the home ventilator dependent patient. Thorax 2006; 61: 369-371.

14. Vitacca M, Escarrabill J, Galavotti G, et al. Home mechanical ventilation patients: a retrospective survey to identify level of burden in real life. Monaldi Arch Chest Dis 2007; 67: 142-147.

15. Ballangrud R, Bogsti WB, Johansson IS. Clients' experiences of living at home with a mechanical ventilator. J Adv Nurs 2009; 65: 425-434.

16. Chiner E, Llombart M, Martínez-García MA, et al. Ventilación mecánica no invasiva en la Comunidad Valenciana: de la teoría a la práctica [Noninvasive mechanical ventilation in valencia, Spain: from theory to practice.] Arch Bronconeumol 2009; 45: 118-122.

17. Escarrabill J. El futuro de la ventilación mecánica domiciliaria: redes o contenedores [Health care support for home mechanical ventilation: networking versus centralization.] Arch Bronconeumol 2007; 43: 527-529.

18. Hammer J. Home mechanical ventilation in children: indications and practical aspects. Schweiz Med Wochenschr 2000; 130: 1894-1902.

19. Fauroux B, Leroux K, Desmarais $\mathrm{G}$, et al. Performance of ventilators for noninvasive positive-pressure ventilation in children. Eur Respir J 2008; 31: 1300-1307.

20. Mah JK, Thannhauser JE, McNeil DA, et al. Being the lifeline: the parent experience of caring for a child with neuromuscular disease on home mechanical ventilation. Neuromuscul Disord 2008; 18: 983-988.

21. García Teresa MA, Gavela Pérez T, Pérez García MJ. Methodology for pediatric non-invasive ventilation in the home. In: Medina A, Pons M, Martimón-Torres F (eds). Non-invasive ventilation in pediatrics (2nd Edn). Barcelona, Ergon, 2009; pp. 000-000.

22. Centre de reference de maladies respiratoires rares. RespiRare. www.respirare.fr Date last accessed: xxx. Date last updated: $x x x$. 